\title{
A prospective study of associations among helping, health, and longevity
}

\author{
Sonja Hilbrand ${ }^{\text {a, b, * }}$, David A. Coall ${ }^{\text {c, d }}$, Andrea H. Meyer a , Denis Gerstorf ${ }^{\mathrm{e}}$, \\ Ralph Hertwig ${ }^{b}$ \\ a Department of Psychology, University of Basel, 4055 Basel, Switzerland \\ b Center for Adaptive Rationality, Max Planck Institute for Human Development, 14195 Berlin, Germany \\ c School of Medical and Health Sciences, Edith Cowan University, Joondalup, WA 6027, Australia \\ d School of Psychiatry and Clinical Neurosciences, University of Western Australia, Crawley, WA 6009, Australia \\ e Department of Psychology, Humboldt University, 10099 Berlin, Germany
}

\section{A R T I C L E I N F O}

\section{Article history:}

Received 21 December 2016

Received in revised form

26 June 2017

Accepted 27 June 2017

Available online 28 June 2017

\section{Keywords:}

Germany

Grandparenting

Grandmother hypothesis

Helping behavior

Health

Longevity

\begin{abstract}
A B S T R A C T
How does helping behavior contribute to the health and the longevity of older helpers? From an evolutionary perspective, the ultimate cause may be rooted in ancestral parenting and grandparenting. These activities may have generalized to a neural and hormonal caregiving system that also enabled prosocial behavior beyond the family. From a psychological perspective, helping others may be associated with healthy aging, which, in turn, contributes to longevity as a proximate cause. Yet little is known about the extent to which mediating factors such as the health benefits of helping behaviors translate into enhanced longevity, particularly in regard to grandparenting. To fill this gap, we conducted mediation analyses (structural equation models) to examine whether grandparenting and supporting others in the social network contributed directly or indirectly (through better health 5-6 years later) to the longevity of older helpers. We drew on longitudinal data from the Berlin Aging Study $(N=516)$, in which older adults in Berlin, Germany, were interviewed at baseline (1990-1993, mean age at entry = 85 years) and continuously followed up until 2009. Results suggest that the associations of both grandparenting and supporting others with enhanced longevity are mediated by better prospective health (indirect effect). The effect of helping was not fully mediated, however-helping was also directly associated with increased longevity independently of the health indicators measured. The results were robust against effects of the helper's preexisting health status and sociodemographic characteristics of participants, their children, and grandchildren. We conclude that better prospective health contributes to the link between helping and longevity, but does not fully account for it. Other potential contributing mechanisms remain to be identified. As populations age across the globe, identifying mechanisms that foster health in old age can help to highlight potential targets for public health interventions.
\end{abstract}

(C) 2017 Elsevier Ltd. All rights reserved.

\section{Introduction}

Many societies around the globe are aging (Glaser et al., 2014). In Europe, for instance, the fast-growing segment of the population is the group aged 65 years or older. This group accounted for $15 \%$ of the total population in 2010, projected to rise to $25 \%$ by 2050 (WHO, 2012). At the same time, the total fertility rate (TFR) has dropped from 2.3 children per woman in 1970 to 1.6 in 2014 (Eurostat, 2016),

\footnotetext{
* Corresponding author. Department of Psychology, University of Basel, Missionsstrasse 60/62, 4055 Basel, Switzerland.

E-mail address: s.hilbrand@unibas.ch (S. Hilbrand).
}

and a growing proportion of the population is childless. One key issue raised by this dramatic demographic transformation is how healthy aging can be promoted in older adults.

One strategy for staying active in old age is to provide childcare for grandchildren or-especially for childless individuals-to support others in the social network. Both forms of helping behavior have been found to be associated with reciprocal benefits in terms of better health or a longer lifespan (Anderson et al., 2014; Hilbrand et al., 2017). Yet most previous work investigating helping behavior has focused on the association to either health or longevity but not both. Furthermore, it commonly is assumed that the beneficial effect of helping on health mediates the beneficial impact of helping 
on longevity, but this mediation hypothesis has not been tested systematically. We fill this gap by examining the indirect and direct paths between helping, health, and longevity. In a first step, we derive potential ultimate causes for these paths from evolutionary theory. Ultimate causes explain why and how a specific mechanism may have evolved over hundreds of generations. In a second step, we complement this line of reasoning by presenting theory and previous empirical findings from the behavioral sciences. These offer a possible proximate explanation for how specific behaviors or circumstances impact individuals within their lifespan. In a third step, we test how both grandparental caregiving and supporting others beyond biological descendants translate into proximate health effects and eventually into longevity benefits.

By grandparenting and grandparental caregiving, we refer to non-custodial, non-intensive grandparental caregiving, defined as time spent looking after a grandchild of any age (Glaser et al., 2014). By supporting and helping others, we mean the provision of regular, but not extensive, instrumental or emotional support to members of the helper's social network beyond biological descendants.

\subsection{Evolutionary perspective: why helping behavior within and beyond the family may have increased human lifespan}

From an evolutionary perspective, it is hypothesized that helping behavior within and beyond kin is ultimately rooted in ancestral parenting and grandparenting (Brown et al., 2011; Chisholm et al., 2016; Hrdy, 2009) and is one of the driving forces underlying human longevity (Hawkes and Coxworth, 2013; Kim et al., 2014). Specifically, the grandmother hypothesis proposes that ancestral as well as contemporary post-reproductive women who help to raise their grandchildren enhance their own inclusive fitness by improving the reproductive success of their children (Hawkes et al., 1997, 1998; Sear and Coall, 2011). Inclusive fitness (Hamilton, 1964) refers to the transmission of a person's genes into future generations via the person's own actions and those of kin who partially share the same genes (e.g., biological relatives). Thus, the longer ancestral post-reproductive grandmothers were alive and helped with childcare, the better their descendants' survival chances (Hrdy, 2001; Sear and Mace, 2008) and the more likely it was that helping behavior and longevity benefits would be transmitted into the future. As post-reproductive women have physiologically fully functional systems (except fertility), it is hypothesized that the inclusive fitness benefits of grandmothering slowed down somatic aging in humans across hundreds of generations (Hawkes and Coxworth, 2013). Grandparenting, especially grandmothering, is thus seen as conferring a selective advantage that drives human longevity at an ultimate level (Kim et al., 2014).

Does the selective advantage of helping within the family also generalize to helping beyond the family, and if so, how could it be explained? One possibility is that through the neural circuitry involved in parenting (see Numan, 2006), prosocial behavior may have generalized across evolution into a neural and hormonal caregiving system (Chisholm et al., 2016; Brown et al., 2011). This caregiving system could be the ultimate foundation of caregiving toward non-kin. On a proximate level, this system operates through emotional processes (Preston and de Waal, 2002), and it seems reasonable to assume that emotional pathways could link helping behavior to regulatory physiological systems (e.g., stress-related neuro-hormonal systems, see Brown and Okun, 2014). This link may, in turn, be one of the proximate mechanisms that couple health and longevity within an individual's lifespan.

Beyond this evolutionary line of reasoning, there are other potential explanations for associations between helping, health, and longevity. We next turn to one account from psychology. In our view, it complements rather than competes with evolutionary theorizing.

\subsection{Psychological perspective: why older adults may benefit from helping}

Socioemotional selectivity theory (SST) predicts that people will shift their goals from accumulating knowledge and skills at younger ages to maintaining social bonds at older ages (Carstensen, 1995). This shift in orientation is associated with healthy aging (Baltes and Carstensen, 1996). Moreover, studies have shown that strengthening relationships with loved ones is key to maintaining quality of life in terminally ill patients, regardless of age (Van der Maas et al., 1991; Wilson et al., 2004). Because physiological and cognitive aging signal the finiteness of life, older adults may be motivated to focus on their social bonds and thus engage in more prosocial behaviors.

Increased helping behavior in older adults may thus indicate a shift toward socioemotional goals (e.g., maintaining social bonds through helping). This shift has been shown to be positively correlated with wellbeing (Baltes and Carstensen, 1996) and stress regulation-which may be a proximate mechanism explaining the concurrent benefits in health and longevity. Indeed, in a recent study of stress-related mortality hazards in adults with a mean age of 71 years, Poulin et al. (2013) found that helping behavior toward friends, neighbors, or relatives who did not live with them overrides the link between stress and mortality: In non-helpers, stress predicted mortality with a hazard ratio of 1.3 ; in helpers, it did not predict mortality (hazard ratio $=0.96$ ).

Yet most previous work has investigated helping behavior and its direct effects on either health or survival, but not the links between all three constructs. In this article, we therefore aim to isolate the indirect effect of helping on longevity via health. Before presenting our empirical analyses, we briefly review findings from the behavioral sciences on the interplay between helping, health, and longevity.

\subsection{Benefits for the older helper: findings from the behavioral sciences}

The non-intensive provision of childcare has been shown to be positively associated with grandparents' cognitive functioning (Arpino and Bordone, 2014), subjective wellbeing (Mahne and Huxhold, 2015), and lower risk of depression (Grundy et al., 2012). Can older adults without children or grandchildren gain similar benefits from, for instance, supporting members of their social network?

Research on helping behavior beyond the nuclear family has yielded a large body of literature indicating that providing voluntary support for others has beneficial effects on a the supporter's health outcomes in a variety of respects (e.g., Brown et al., 2008; Kahana et al., 2013; Morrow-Howell et al., 2003; Musick et al., 1999; Tanskanen and Danielsbacka, 2016). Concerning older adults in particular, Anderson et al. (2014) reviewed 73 studies and found that, for people aged 50 years and older, volunteering was consistently associated with reduced symptoms of depression, better selfreported health, fewer functional limitations, or enhanced longevity (for similar results, see Okun et al., 2013). The literature thus suggests that helping behavior has health or longevity benefits. However, it remains unclear whether longevity benefits are the result of the health benefits (indirect effects) or whether helping is directly associated with longevity. Moreover, some boundaries to the beneficial effects of helping have been identified.

Full-time grandparental caregiving, for instance, can be highly stressful, depleting grandparents' material and psychological 
resources and compromising their physical and mental health (Taylor et al., 2016). Findings of an inverse U-shaped relationship between the extent of grandparenting and wellbeing (see Coall and Hertwig, 2010) have been corroborated by Glaser et al. (2014). They found that both grandparents who co-reside with grandchildren (providing custodial childcare) and grandparents who do not provide any grandchild care are likely to report poor. When considering the effects of grandparental caregiving, it is therefore important to quantify caregiving intensity. Non-intensive levels of caregiving are most likely to be associated with benefits. This may be especially true of older grandparents, who may be more vulnerable to adverse effects of intensive caregiving. The same logic applies to help provided beyond the family. Helpers only benefit as long as their helping does not exhaust them physically or psychologically (Post, 2005). Furthermore, it is essential to take preexisting health and socioeconomic characteristics into account; these factors are known to affect associations between helping behavior and health outcomes (Glaser et al., 2014; Hughes et al., 2007). Another issue when investigating helping behavior beyond the family is that the type and availability of formal volunteering often differs considerably across countries or regions (Stadelman-Steffen and Freitag, 2011). It is therefore useful to investigate a type of 'volunteering' that is prevalent in most communities, such as supporting others in the wider social network. From a societal point of view, this type of social support is especially valuable. Furthermore, as fertility rates drop and the number of disability-free years rises, there is likely to be an increase in the numbers of older adults who either do not have grandchildren or do not live near to their grandchildren (e.g., due to divorce or geographic mobility) but are willing and able to allocate resources to care for others.

All of these issues will eventually need to be factored into an encompassing analysis of the individual and collective effects of helping behaviors within and beyond the family. Our goal is to take some further steps in this direction. Our brief review suggests that helping behavior at older ages-and under certain conditions-is associated with healthy aging, and thus indirectly with enhanced longevity. This pathway has not, however, been systematically investigated. Moreover, it remains unclear to what extent health benefits translate into enhanced longevity. Health may be a major driver, but does it fully account for the apparent longevity benefits of helping?

\section{Hypotheses}

Assuming that caregiving offered a selective advantage in humans' evolutionary past and that contemporary humans carry the genetic endowment for helping behavior, we showed in a previous investigation that the act of caregiving has measurable longevity effects for helpers today (Hilbrand et al., 2017). Specifically, mortality was 33\% lower for caregiving grandparents than for non-caregiving grandparents and non-grandparents, with a hazard ratio of 0.63 . Similar results emerged for older parents who gave instrumental help to their adult children and for childless older helpers who supported others in their social network. In the present investigation, we examine this association further by testing whether the link between helping and longevity is mediated by better prospective health (see Fig. 1).

Working on the assumption that human longevity is rooted in parenting and grandparenting (ultimate level), and that helping behavior is associated with better health in older adults (proximate level, see SST), we examined whether helping behavior contributes indirectly (via better health) to longevity. Specifically, we tested two hypotheses. The first hypothesis states that, in grandparents, the associations of non-intensive grandparenting and supporting others with enhanced longevity are both mediated by better

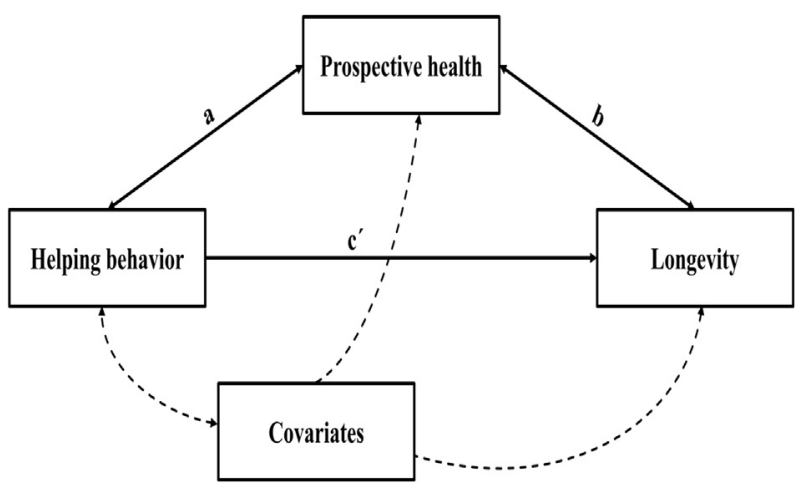

Fig. 1. Mediation model of the relationship between helping behavior and longevity (direct effect, $c^{\prime}$ ), mediated by health (indirect effect, ab), including covariates.

prospective health on a proximate level (indirect effect; ab path). Going beyond our previous investigation, we test both forms of helping (grandparenting and supporting others in the wider social network) in a single model. This enables us to explore their independent effects on health and longevity in grandparents. The second hypothesis states that, in childless older adults, the association of providing moderate levels of support to the social network beyond biological descendants with longevity is mediated by better prospective health on a proximate level (indirect effect, ab path). In examining these hypotheses, we focused on older adults because health-related declines (e.g., in cognitive abilities or functional health) become most salient as the end of life draws closer (Gerstorf et al., 2013; Kleemeier, 1962).

\section{Methods}

\subsection{Data}

Data were drawn from the longitudinal Berlin Aging Study, BASE (Lindenberger et al., 2010). BASE is a multidisciplinary investigation of the physical, cognitive, and social characteristics of people aged 70 years and older living in former West Berlin. The BASE dataset contains extensive information on a range of health and social conditions obtained from participants (generation 1, G1), as well as information provided by $\mathrm{G} 1$ about their children (generation 2, G2) and grandchildren (generation 3, G3). The BASE sample was randomly selected from the records of the West Berlin registration office. Those who agreed to participate completed interviews and medical tests at their homes, doctors' practices, and hospitals at baseline (interview time 1 [T1] between 1990 and 1993). The assessments were repeated at approximately 2-year intervals and participants were followed up until 2009 (interview time 8 [T8]). Detailed descriptions of the variables and procedures used are available elsewhere (Lindenberger et al., 2010; see also https:// www.base-berlin.mpg.de/en). Ethical approval for data collection and permission for subsequent use was granted by the Berliner Ärztekammer (Berlin physician commission) prior to the present study prior to the present study.

As is often the case in longitudinal study designs, most cases of longitudinal missing data were due to participant attrition (mortality or moving away from Berlin). The latest update on mortality in 2009 revealed that 463 of the initial 516 participants had died (89.7\%), 33 were alive (6.4\%), and 20 (3.9\%) were unaccounted for (further details on selectivity and imputation of missing data are provided in the online Supplementary Material (SM, see, Table S3)). 


\subsection{Measurements}

\subsubsection{Dependent variable}

Longevity was measured prospectively and indicates how many years participants lived following the interview at time 1 [T1] (known until 2009, estimated until 2015 when the last survivor was approximated to have died).

\subsubsection{Independent variables}

Grandparenting indicates the frequency of grandparental caregiving in the 12 months prior to T1 and is defined as looking after or doing something with the grandchild (G3) without the parents (G2) being present. This variable ranges from 1 (never) to 7 (every day). Note that there were no cases of grandparental caregiving on a daily basis; in other words, our sample did not include any primary or custodial caregivers.

Supporting others indicates the amount of instrumental support (e.g., aid with housework or fixing things) and/or emotional support (e.g., cheering someone up) given to others in the social network in the 3 months prior to T1. This variable ranges from 0 (no support given) to 6 (maximum number of supporting activities given), indicating how many of six questions (see the SM for details) were answered with yes. Note that the maximum score represents a moderate amount of help, which is not expected to exhaust the helper.

\subsubsection{Mediator}

Health index at interview time 3 [T3] is a Z-standardized composite scale representing health 5-6 years after T1. Because health is a multi-dimensional construct, we included four subscales reflecting physical and mental health: comorbidity (number of physician-made diagnoses), functional health (Instrumental Activities of Daily Living, IADL), cognitive functioning (Mini Mental State Examination, MMSE), and depression (Hamilton Rating Scale for Depression, HAM-D). These subscales were selected via factor analysis. More details on the subscales and the selection procedure are provided in the SM (Tables S1 and S2).

\subsubsection{Covariates}

We controlled for a set of covariates at T1 across all three generations. The covariates have previously been shown to be associated with longevity (Aichele et al., 2016; Gerstorf et al., 2013), health and aging (Lindenberger, 2014), or grandparental caregiving (Coall et al., 2009, 2014; Tanskanen and Danielsbacka, 2012).

At the participant level (G1), the covariates were health index at T1 (constructed equivalently to health index at T3), age, sex, education level, relationship status (with versus without partner), and income. Age at transition to grandparenthood was defined with respect to the birth of the first grandchild (becoming a grandparent at an early age has been shown to be associated with both worse health and higher mortality, see Christiansen, 2014; Coall et al., 2009). The variables number of children and number of grandchildren covered all living children and grandchildren to account for all potential caregiving opportunities. Finally, the sum of different kinds of support received from others in the social network in the 3 months prior to $\mathrm{T} 1$ was encoded (equivalently to the measure described above).

At the child level (G2), the covariates (averaged over all children), were age, sex, education level, and relationship status (with versus without partner). At the grandchild level (G3), the covariates were age of the youngest grandchild (because grandparenting is typically focused on the youngest), sex, education level, and geographic proximity to the grandparent (averaged over all grandchildren). Descriptive data on all measures are presented in Table 1. More details on the computation and coding of these variables are provided in the SM.

\subsection{Statistical analyses}

We used structural equation modeling functions as implemented in the $\mathrm{R}$ software package lavaan ( $\mathrm{R}$ Development Core Team; Rosseel, 2012) to test our hypotheses. These functions account for missing data using the full information maximum likelihood (FIML) method. To avoid biases toward younger and healthier individuals and to make use of complete datasets without missing information, we used SPSS v. 22.0 (IBM Corp. Armonk, NY) to conduct descriptive, correlational, and additional analyses on multiple imputation datasets (see the SM for details).

First, variables with skewed distributions were logarithmically transformed. Second, model fitting indicated that linear rather than curvilinear associations were appropriate for investigating the relationship between grandparenting/supporting others and longevity (see Table S5 and Figs. S1 and S2 in the SM). Third, we conducted a factor analysis extracting and testing the variables best representing the multi-dimensional construct of health (more details on this analysis are available in the SM, Table S1). In addition, we separately tested the predictive strength of each extracted health subscale with respect to longevity, compared with the cumulative effect of the health index at T3 (see Table S2 in the SM). Fourth, we computed correlation coefficients between the independent variables, the mediator, and the dependent variables (see Table 2). Finally, we tested both hypotheses by conducting adjusted multiple mediation analyses. This procedure simultaneously calculates unstandardized regression coefficients for all paths of the mediation model, thereby adjusting for the covariates in the model. Confidence intervals of coefficients denoting indirect effects are based on the bootstrapping sampling method (using 5000 samples). Like regression coefficients in linear regressions, the greater the coefficient's distance from 0 the stronger the association; positive associations are indicated by positive coefficients, negative associations by negative coefficients.

The first model, which tested hypothesis 1, included grandparenting and supporting others as independent variables, the health index at T3 as the mediator, and longevity as the dependent variable. Only grandparents were included in this analysis $(n=312)$. The second model, which tested hypothesis 2, included supporting others as the independent variable, the health index at T3 as the mediator, and longevity as the dependent variable. Only childless participants were included in this analysis $(n=153)$ to ensure that the support did not go to children or grandchildren. Covariates in both models were socioeconomic characteristics at the grandparent, child, and grandchild levels, and support received from others.

\section{Results}

\subsection{Link between helping behavior, health, and longevity}

Correlational results (with no covariates included) are presented in Table 2. Both independent variables (grandparenting and supporting others), the mediator (health index at T3), and the dependent variable (longevity) were positively and significantly intercorrelated.

\subsection{Mediating role of prospective health}

Model 1 tested the hypothesis that, in grandparents, the associations of both grandparenting and supporting others with longevity are mediated by prospective health. The regression coefficients summarized in Fig. 2 showed that higher levels of 
Table 1

Descriptive statistics of the independent variables, mediator, dependent variable, and covariates $(N=516)$.

\begin{tabular}{|c|c|c|c|}
\hline Participants (G1) & Mean or percentage & Range & $n$ \\
\hline Longevity (in years) & 6.52 & $0-22$ & 516 \\
\hline Grandparenting & 2.44 & $1-6$ & 312 \\
\hline Supporting others & 2.38 & $0-6$ & 516 \\
\hline Health index at T3 (Z-standardized) & 0 & $-1.52-1.78$ & 516 \\
\hline Female & $50.00 \%$ & - & 516 \\
\hline Age & 84.92 & $70-103$ & 516 \\
\hline Age at transition to grandparenthood & 57.22 & $31-89$ & 312 \\
\hline Number of children & 1.28 & $0-11$ & 516 \\
\hline Number of grandchildren & 1.83 & $0-22$ & 516 \\
\hline Education level & 1.56 & $1-5$ & 516 \\
\hline Without partner & $70.20 \%$ & - & 516 \\
\hline Income & 3.50 & $1-5$ & 516 \\
\hline Support received from others & 3.23 & $0-6$ & 516 \\
\hline Health index at T1 (Z-standardized) & 0 & $-1.56-1.85$ & 516 \\
\hline \multicolumn{4}{|l|}{ Children (G2) } \\
\hline Age & 53.20 & $23-83$ & 379 \\
\hline Female & $42.00 \%$ & - & 379 \\
\hline Education level & 1.98 & $1-5$ & 379 \\
\hline Without partner & $35.50 \%$ & - & 379 \\
\hline \multicolumn{4}{|l|}{ Grandchildren (G3) } \\
\hline$\overline{\text { Age }}$ & 19.41 & $0-46$ & 312 \\
\hline Education level & 1.65 & $1-5$ & 312 \\
\hline Proximity & 5.28 & $1-8$ & 312 \\
\hline
\end{tabular}

Table 2

Pearson correlations ( $\mathrm{r}$ coefficients) between grandparenting, supporting others, the health index at $\mathrm{T} 3$, and longevity.

\begin{tabular}{llll}
\hline & Grandparenting & Supporting others & Health index at T3 \\
\hline Grandparenting & 1 & & \\
Supporting others & $0.67^{* * *}$ & 1 & 1 \\
Health index at T3 & $0.70^{* * *}$ & $0.63^{* * *}$ & $0.81^{* * *}$ \\
Longevity & $0.66^{* * *}$ & $0.72^{* * *}$ & \\
\hline
\end{tabular}

grandparenting and of supporting others were significantly and independently associated with better health (a paths) and that better health was significantly associated with increased longevity (b path). The coefficients of these indirect effects (ab paths) differed significantly from 0 ( $B_{\text {grandparenting }}=0.23,95 \%$ confidence interval $(\mathrm{CI})=0.12-0.38, \mathrm{p}<0.001 ; \mathrm{B}_{\text {supporting others }}=0.38,95 \%$ $\mathrm{CI}=0.22-0.56, \mathrm{p}<0.001)$. At the same time, the coefficients of the direct effects ( $c^{\prime}$ paths) of the two predictors on longevity were also

${ }^{* * *} \mathrm{p}<0.001$

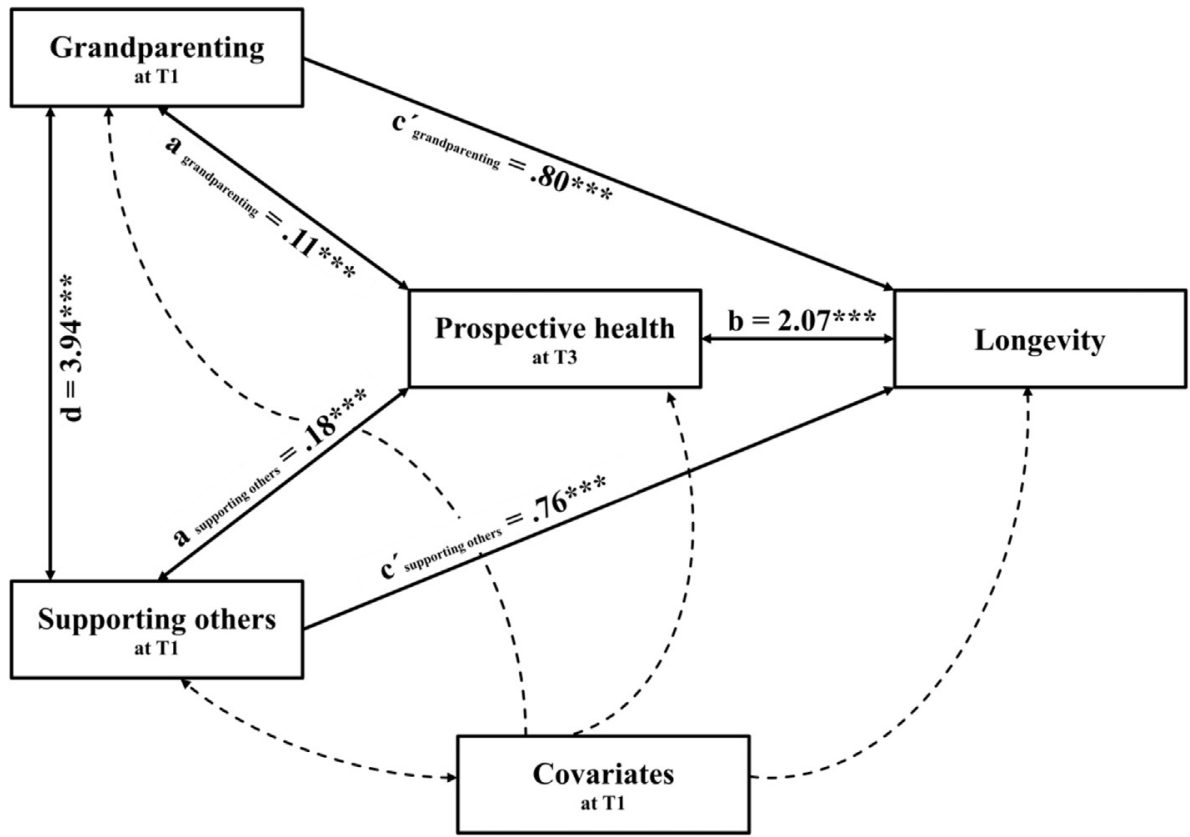

Fig. 2. Regression coefficients from mediation model 1. The model tested indirect $(a b)$ and direct $\left(c^{\prime}\right)$ effects of grandparenting and supporting others on longevity in grandparents, adjusting for the following covariates: sex (G1, G2, G3), age (G1, G2, G3), age at transition to grandparenthood (G1), number of children and grandchildren (G1), relationship status (G1, G2), education level (G1, G2, G3), income (G1), support received from others (G1), health index at T1 (G1), and proximity (G3). Note ***p $<0.001$. 
significantly positive. This means that the effect of helping was not fully mediated. Prospective health mediated $22 \%$ of the relationship between the two predictors and longevity. The model explained $88 \%$ of the total variance in longevity (adjusted $R^{2}$ ).

As both predictors independently contributed to longevity, there was no superior effect of one predictor over the other. Moreover, the predictors were significantly associated (d path) indicating that many grandparents who provided care for grandchildren also supported others in their social network. However, providing both forms of help did not yield an increased longevity benefit relative to providing only grandparental care (see the additional analyses in the SM).

Model 2 tested the hypothesis that, in childless participants, the association of supporting others beyond biological descendants with longevity is mediated by prospective health. The regression coefficients summarized in Fig. 3 again showed that higher levels of supporting others were significantly associated with better health (a path) and that better health was significantly associated with enhanced longevity (b path). The coefficient of this indirect effect (ab path) differed significantly from $0(\mathrm{~B}=0.58,95 \% \mathrm{CI}=0.27-0.81$, $\mathrm{p}<0.001$ ). Again, the coefficient of the direct effect ( $c^{\prime}$ path) of the predictor on longevity was significantly positive. This means that the effect of helping was not fully mediated. Prospective health mediated $29 \%$ of the relationship between supporting others and longevity, and the model explained $81 \%$ of the total variance in longevity (adjusted $R^{2}$ ).

Overall, grandparenting and supporting others were both significantly associated with longevity, and these associations were partially mediated by prospective health. Of the subscales included in the mediator (health index at T3), functional health proved to have the strongest association with longevity (see Table S2 in the SM).

In addition, results of a mediation analysis with a sample restricted to grandchildren younger than 17 years (SM, Fig. S4) suggest that the association between grandparenting and longevity was not attributable to the fact that grandparental caregiving is usually associated with younger grandchildren. Moreover, tests for interactions (age $\times$ health, sex $\times$ helping, and relationship status $\times$ helping) reveal that in the present dataset the link between helping and longevity was not due to either younger and healthier or females or persons cohabitating with a partner providing more care (see the SM, Tables S6-S11 and Fig. S5). Testing the direction of the effect further, results of a mediation analysis with health index at T1 as predictor (SM, Fig. S7) indicates that health at baseline did not predict whether grandparents provided care for their grandchildren at T3. In a nutshell, grandparenting contributes to enhanced longevity and this effect cannot be explained in terms of better health at baseline alone.

\section{Discussion}

Evolutionary theorizing (the grandmother hypothesis and the theory of a neural and hormonal caregiving system) provides an ultimate explanation of why and how helping behavior evolved to be associated with longevity. Complementing this line of reasoning, psychological theorizing (e.g., socioemotional selectivity theory) offers a proximate explanation as to why older adults, in particular, may gain health and longevity benefits from helping others. To our knowledge, this investigation is the first to empirically examine the concurrent associations between helping, health, and longevity based on evolutionary and psychological reasoning. Both grandparenting and supporting others beyond biological descendants are associated with increased longevity of the helper. We found that these associations are partially mediated by better prospective health. Next, we discuss other factors potentially mediating the association between helping behavior and longevity that are not contained in the BASE dataset.

\subsection{Other factors associated with helping behavior and longevity}

Although prospective health and longevity were highly correlated (Pearson correlation, $r=0.81$ ), health mediated only $22 \%$ of the association between helping behavior and longevity in grandparents and $29 \%$ of the association in childless older adults. This finding strongly suggests that the translation of health benefits into enhanced longevity often implicitly assumed in previous work cannot be taken for granted. Through what other pathways might helping behavior increase longevity?

Although the BASE health indices do include indicators of physical and emotional health (i.e., depression), indicators of stress are not available. Since emotional regulatory systems involve pathways linked to the human stress response, investigating stress

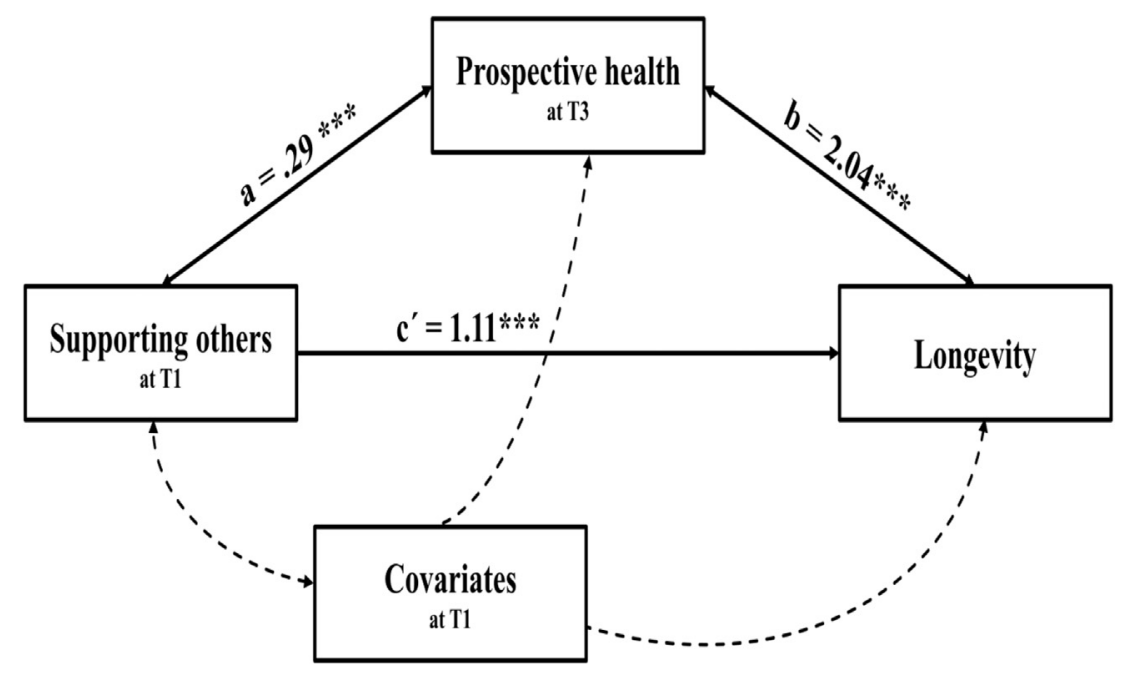

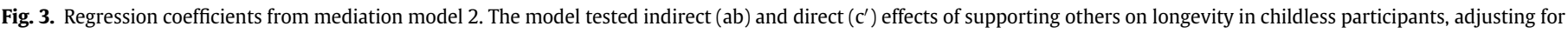
the following covariates (all at G1): sex, age, relationship status, education level, income, support received from others, and health index at T1. Note ${ }^{* * *} \mathrm{p}<0.001$. 
and its triggers may further illuminate the link between helping behavior, health, and longevity. A recent study identifies prosocial behavior as an effective stress-reduction strategy because it influences biological systems, including stress-regulating hormones such as oxytocin (Raposa et al., 2016). This possibility is in line with findings that helping behavior is a stress buffer that in turn boosts survival (Poulin et al., 2013). Both studies complement the evolutionary argument that the human caregiving system ultimately evolved from (grand)parenting and that it proximately operates through emotion (e.g., compassion) and stress-regulatory systems (e.g., oxytocin), thus influencing health and longevity.

Another factor potentially involved in the link between helping behavior and longevity is the relationship between care provider and receiver. For example, maintaining quality contact between paternal grandparents and grandchildren, who are often alienated during re-partnering and step-family formation, is beneficial to the behavioral adjustment and mental health of both (Attar-Schwartz et al., 2009; Bates and Taylor, 2012). Social strain afflicting intergenerational relationships not only leads to declines in health (Tun et al., 2013) but also decreases the probability of helping behavior in these relationships (Coall et al., 2014). Therefore, the quality of emotional relationships may further shape the association between helping and longevity (Merz et al., 2007).

Participants' motives for helping may also play a key role in whether helping behavior results in health and longevity benefits. Such benefits have previously been found only when volunteering is other-oriented rather than reciprocity-oriented (Konrath et al., 2012; for further motivational aspects, see Fung and Carstensen, 2004). From an evolutionary perspective, it is plausible that other-orientation evolved within the family (see caregiving system). It follows that the engine behind helping behavior is not primarily reciprocity based (see Kurzban et al., 2015, for a review of human altruistic behavior). Indeed, results from health psychology suggest that frustrated expectations of reciprocal reward can override the positive effects of helping and potentially even lead to depression in the helper (Keller, 2002). Thus, whether the help provided is other-oriented or reciprocity-oriented may further shape the association between helping and longevity.

These bio-psycho-social factors may play an important complementary role in the association between helping behavior, health, and longevity. Examination of multiple proximate pathways may reveal more details of the causal mechanisms underlying the associations of helping within and beyond the family with longevity. In this study, we have taken a first step in this direction.

\subsection{Strengths, limitations and future research}

This investigation has several strengths. First, we brought together evolutionary and psychological theorizing, and showed that they complement rather than compete with each other in explaining the associations between helping, health, and longevity. Second, we used proxies of both physical and mental health to reflect the multi-dimensional construct of health. Focusing on a single aspect of health is not sufficient to detect effects on longevity, as the impact of physical and mental health on longevity is cumulative (Aichele et al., 2016, see also Table S2 in the SM for additional analyses on each health subscale). Third, our health measures were not only based on self-reports, but included physician-made diagnoses of moderate to severe chronic illnesses (as determined in clinical examinations, supported by additional laboratory analysis of blood and saliva samples) and performancebased measures of cognitive functioning. Fourth, we were able to capitalize on the longitudinal nature of the BASE dataset. This allowed us to rule out the explanation that the association between helping and longevity was due to participant's better preexisting health (see the mediation analysis with health as predictor in the SM, Fig. S7). The longitudinal nature permitted a prospective investigation of how helping behavior at $\mathrm{T} 1$ was associated with subsequent health at T3 and consequently impacted longevity. The BASE data also allowed us to account for preexisting health and socioeconomic characteristics of participants, all their children, and grandchildren (T1). In many previous studies, in contrast, the closest or youngest grandchild was chosen. Taking these characteristics into account across all three generations provides a more detailed representation of the helpers and their social and familial networks than has previously been achieved. Fifth, the BASE dataset allowed us to account for support received from others, thus controlling for reciprocity. Receiving support in old age is hypothesized to contribute to longevity independently of health. Specifically, grandparents are assumed to allocate more resources to those grandchildren who are most likely to reciprocate (see rational grandparent model, Friedman et al., 2008), thus ensuring grandparental wellbeing in old age. Because we controlled for support received in both of our models, this competing explanation can be ruled out. Furthermore, from an evolutionary perspective, it is the provision of help that translates into health and longevity benefits, rather than receipt alone (Brown et al., 2003).

Several limitations of our study warrant acknowledgment. As mentioned above, additional bio-psycho-social factors (e.g., stressrelated hazards, motivation for providing care, and relationship quality) may mediate the association between helping and longevity. No data on these factors were available in BASE. Future investigations may choose to test the proximate physiological pathways explaining why prosocial behavior has the potential to influence longevity via health (see Introduction) under laboratory conditions (e.g., by measuring oxytocin).

Another limitation is that we tested the hypotheses in two specific groups (i.e., grandparents and childless older adults). Therefore, we cannot be certain that the results will generalize beyond these populations. This question must be explored by investigating the triangle of helping, health, and longevity in other groups, such as older adults with children but no grandchildren. Furthermore, it is possible that helping behavior is associated with longevity in younger and healthy people but not in older and less healthy people. We tested for an interaction between age and health (see the SM) and found that younger and healthier participants were indeed more likely to benefit from helping. We therefore included an interaction term (age $\times$ health) in both models; the results remained robust. That is, longevity benefits were not due to younger age and better preexisting health.

A final issue concerns the extent to which the caregiving variable grandparenting is confounded with general social interactions with grandchildren. Our measure of grandparenting may have included occasions when grandparents (G1) simply met their grandchildren (G3) without the parents (G2) being present. Although we observed similar results in a subsample of grandchildren aged under 17 years, who are more likely to require caregiving than older grandchildren (see the SM), the observed effects may be biased by the social rather than instrumental dimensions of the interaction. The variable supporting others captures helping behavior (instrumental and emotional support) more clearly. Future studies examining helping behavior under laboratory conditions may be able to separate the social from the instrumental dimensions of grandparenting more clearly than was possible here.

Notwithstanding these limitations, our findings raise the possibility that actively promoting helping behavior within and beyond the family may be conducive to healthy aging and longevity. 


\subsection{Conclusion}

Our findings suggest that helping behavior is not only associated with longevity, but also supports healthy aging. From a public health perspective, this is good news. Older adults who engage in helping behavior could age actively, with more years in better health. Before these empirical regularities can be translated into targeted public health interventions, however, transdisciplinary efforts are needed to unravel more of the proximate mechanisms underlying the relationship between helping behavior and longevity.

\section{Competing interests}

We have no conflict of interest.

\section{Authors' contributions}

All authors jointly designed the research and approved the final manuscript; S.H. and A.H.M. analysed the data. S.H. drafted the manuscript; D.A.C., R.H. and D.G. revised the manuscript.

\section{Funding}

This manuscript reports data from the Berlin Aging Study (BASE; www.base-berlin.mpg.de). BASE was initiated by Paul B. Baltes, in collaboration with Hanfried Helmchen, psychiatry; Elisabeth Steinhagen-Thiessen, internal medicine and geriatrics; and Karl Ulrich Mayer, sociology. Financial support came from the Max Planck Society; the Free University of Berlin; the German Federal Ministry for Research and Technology (1989-1991, 13 TA 011 _ 13 TA 011/A); the German Federal Ministry for Family, Senior Citizens, Women, and Youth (1992-1998, 314-1722-102/9_314-1722-102/ 9a); and the Berlin-Brandenburg Academy of Sciences' Research Group on Aging and Societal Development (1994-1999).

There was no involvement by these funding sources in the research design or preparation of this manuscript.

\section{Acknowledgements}

We are grateful to Martin Becker for helping us navigate through the BASE dataset and to Susannah Goss and Toni Wain for editing the manuscript.

\section{Appendix A. Supplementary data}

Supplementary data related to this article can be found at http:// dx.doi.org/10.1016/j.socscimed.2017.06.035.

\section{References}

Aichele, S., Rabbitt, P., Ghisletta, P., 2016. Think fast, feel fine, live long: a 29-year study of cognition, health, and survival in middle-aged and older adults. Psychol. Sci. 27 (4), 518-529. http://dx.doi.org/10.1177/0956797615626906.

Anderson, N.D., Damianakis, T., Kröger, E., Wagner, L.M., Dawson, D.R., Binns, M.A., Bernstein, S., Caspi, E., Cook, S.L., The BRAVO Team, 2014. The benefits associated with volunteering among seniors: a critical review and recommendations for future research. Psychol. Bul. 140, 1505-1533. http://dx.doi.org/10.1037/ a0037610.

Arpino, B., Bordone, V., 2014. Does grandparenting pay off? The effect of child care on grandparents' cognitive functioning. J. Marriage Fam. 76 (2), 337-351. http:// dx.doi.org/10.1111/jomf.12096.

Attar-Schwartz, S., Tan, J.P., Buchanan, A., Flouri, E., Griggs, J., 2009. Grandparenting and adolescent adjustment in two-parent biological, lone-parent, and stepfamilies. J. Fam. Psychol. 23, 67-75. http://dx.doi.org/10.1037/a0014383.

Baltes, M.M., Carstensen, L.L., 1996. The process of successful aging. Ageing Soc. 16, 397-422. http://dx.doi.org/10.1017/S0144686X00003603.

Bates, J.S., Taylor, A.C., 2012. Grandfather involvement and aging men's mental health. Am. J. Men's Health 6, 229-239. http://dx.doi.org/10.1177/
1557988311430249

Brown, S.L., Brown, R.M., House, J.S., Smith, D.M., 2008. Coping with spousal loss: potential buffering effects of self-reported helping behavior. Pers. Soc. Psychol. Bull. 34 (6), 849-861. http://dx.doi.org/10.1177/0146167208314972.

Brown, S.L., Brown, R.M., Preston, S.D., 2011. The human caregiving system: a neuroscience model of compassionate motivation and behavior. In: Brown, S.L., Brown, R.M., Penner, L.A. (Eds.), Moving beyond Self-interest: Perspectives from Evolutionary Biology, Neuroscience, and the Social Sciences. Oxford University Press, New York, pp. 75-88. http://dx.doi.org/10.1093/acprof:oso/ 9780195388107.001.0001.

Brown, S.L., Nesse, R.M., Vinokur, A.D., Smith, D.M., 2003. Providing social support may be more beneficial than receiving it: results from a prospective study of mortality. Psychol. Sci. 14 (4), 320-327. http://dx.doi.org/10.1111/14679280.14461.

Brown, S.L., Okun, M., 2014. Using the caregiver system model to explain the resilience-related benefits older adults derive from volunteering. In: Kent, M. Davis, M.C., Reich, J.W. (Eds.), The Resilience Handbook. Approaches to Stress and Trauma. Routledge, New York, pp. 171-182.

Carstensen, L.L., 1995. Evidence for a life-span theory of socioemotional selectivity. Curr. Dir. Psychol. Sci. 4, 151-156. http://dx.doi.org/10.1111/14678721.ep11512261.

Chisholm, J.S., Coall, D.A., Atkinson, L., 2016. Mother-infant cultural group selection. Behav. Brain Sci. 39, e35. http://dx.doi.org/10.1017/S0140525X15000084 e35.

Christiansen, S.G., 2014. The association between grandparenthood and mortality. Soc. Sci. Med. 118, 89-96. http://dx.doi.org/10.1016/j.socscimed.2014.07.061.

Coall, D.A., Hertwig, R., 2010. Grandparental investment: past, present, and future. Behav. Brain Sci. 33 (01), 1-59. http://dx.doi.org/10.1017/s0140525x09991105.

Coall, D.A., Hilbrand, S., Hertwig, R., 2014. Predictors of grandparental investment decisions in contemporary Europe: biological relatedness and beyond. PLoS ONE 9 (1), e84082. http://dx.doi.org/10.1371/journal.pone.0084082.

Coall, D.A., Meier, M., Hertwig, R., Wänke, M., Höpflinger, F., 2009. Grandparental investment: the influence of reproductive timing and family size. Am. J. Hum. Biol. 21 (4), 455-463. http://dx.doi.org/10.1002/ajhb.20894.

Eurostat, 2016. Total Fertility Rates. http://ec.europa.eu/eurostat/statisticsexplained/index.php/File:Total_fertility_rate_1960\%E2\%80\%932014_(live_ births_per_woman)_YB16.png (Accessed 9 September 2016).

Friedman, D., Hechter, M., Kreager, D., 2008. A theory of the value of grandchildren. Ration. Soc. 20, 31-61. http://dx.doi.org/10.1177/1043463107085436.

Fung, H.H., Carstensen, L.L., 2004. Motivational changes in response to blocked goals and foreshortened time: testing alternatives to socioemotional selectivity theory. Psychol. Aging 19 (1), 68-78.

Gerstorf, D., Ram, N., Lindenberger, U., Smith, J., 2013. Age and time-to-death trajectories of change in indicators of cognitive, sensory, physical, health, social, and self-related functions. Dev. Psychol. 49 (10), 1805-1821. http://dx.doi.org/ $10.1037 / \mathrm{a} 0031340$.

Glaser, K., di Gessa, G., Tinker, A., 2014. Grandparenting in Europe. The Health and Wellbeing of Grandparents Caring for Grandchildren: the Role of Cumulative Advantage/disadvantage. Economic and Social Research Council Report. https:// www.grandparentsplus.org.uk/wp-content/uploads/2011/03/ESR-GrandparentReport_Oct14-2.pdf (Accessed 4 April 2016)

Grundy, E.M., Albala, C., Allen, E., Dangour, A.D., Elbourne, D., Uauy, R., 2012 Grandparenting and psychosocial health among older Chileans: a longitudinal analysis. Aging Ment. Health 16 (8), 1047-1057. http://dx.doi.org/10.1080/ 13607863.2012.692766.

Hamilton, W.D., 1964. The genetical evolution of social behaviour (I and II). J. Theor. Biol. 7, 1-52. http://dx.doi.org/10.1016/0022-5193(64)90038-4, 10.1016/00225193(64)90039-6.

Hawkes, K., Coxworth, J.E., 2013. Grandmothers and the evolution of human longevity: a review of findings and future directions. Evol. Ant. Issues News Rev. 22 (6), 294-302. http://dx.doi.org/10.1002/evan.21382.

Hawkes, K., O'Connell, J.F., Blurton Jones, N.G., 1997. Hadza women's time allocation, offspring provisioning, and the evolution of long postmenopausal life spans. Curr. Anthrop. 38 (4), 551-577. http://dx.doi.org/10.1086/204646.

Hawkes, K., O'Connell, J.F., Blurton Jones, N.G., Alvarez, H., Charnov, E.L., 1998. Grandmothering, menopause, and the evolution of human life histories. Proc. Nat. Acad. Sci. 95 (3), 1336-1339. http://dx.doi.org/10.1073/pnas.95.3.1336.

Hilbrand, S., Coall, A.D., Gerstorf, D., Hertwig, R., 2017. Caregiving within and beyond the family is associated with lower mortality for the caregiver. Evol. Hum. Behav. 38 (3), 397-403. http://dx.doi.org/10.1016 j.evolhumbehav.2016.11.010.

Hrdy, S.B., 2009. Mothers and Others: the Evolutionary Origins of Mutual Understanding. Harvard University Press, Cambridge.

Hrdy, S.B., 2001. Mothers and Others. http://www.cogsci.ucsd.edu/classes/WI12/ COGS1/readings/04-COGS1_Deak-Social_Infant_Hrdy_2001.pdf (Accessed 17 September 2016)

Hughes, M.E., Waite, L.J., Lapierre, T.A., Luo, Y., 2007. All in the family: the impact of caring for grandchildren on grandparents' health. J. Geront. B Psychol. Sci. Soc. Sci. 62, 108-119. http://dx.doi.org/10.1093/geronb/62.2.s108.

Kahana, E., Bhatta, T., Lovegreen, L.D., Kahana, B., Midlarsky, E., 2013. Altruism, helping, and volunteering: pathways to well-being in late life. J. Aging Health 25 (1), 159-187. http://dx.doi.org/10.1177/0898264312469665.

Keller, M., 2002. Von Agency zu Selbstkontakt (From agency to self-contact). IBP Newsletter. http://www.ibp-institut.ch/fileadmin/media/downloads/ueber_IBP Artikel/Grundlagen/Artikel_von_Agency_zu_Selbstkontakt_MK_100519.pdf (Accessed 4 July 2013). 
Kim, P.S., McQueen, J.S., Coxworth, J.E., Hawkes, K., 2014. Grandmothering drives the evolution of longevity in a probabilistic model. J. Theor. Biol. 353, 84-94. http://dx.doi.org/10.1016/j.jtbi.2014.03.011.

Kleemeier, R.W., 1962. Intellectual changes in the senium. Proc. Soc. Stat. Sect. 1, $290-295$.

Konrath, S., Fuhrel-Forbis, A., Lou, A., Brown, S.L., 2012. Motives for volunteering are associated with mortality risk in older adults. Health Psychol. 31 (1), 87-96. http://dx.doi.org/10.1037/a0025226.

Kurzban, R., Burton-Chellew, M.N., West, S.A., 2015. The evolution of altruism in humans. Ann. Rev. Psychol. 66 (1), 575-599. http://dx.doi.org/10.1146/annurevpsych-010814-015355.

Lindenberger, U., 2014. Human cognitive aging: corriger la fortune? Science 346 (6209), 572-578. http://dx.doi.org/10.1126/science.1254403.

Lindenberger, U., Smith, J., Mayer, K.U., Baltes, P.B., 2010. Die Berliner Altersstudie (The Berlin Aging Study). Akademie Verlag, Berlin.

Mahne, K., Huxhold, O., 2015. Grandparenthood and subjective well-being moderating effects of educational level. J. Geront. B Psy. Sci. Soc. Sci. 70 (5) 782-792. http://dx.doi.org/10.1093/geronb/gbu147.

Merz, E.-M., Schuengel, C., Schulze, H.-J., 2007. Intergenerational solidarity: an attachment perspective. J. Aging Stud. 21, 175-186. http://dx.doi.org/10.1016 j.jaging.2006.07.001.

Morrow-Howell, N., Hinterlong, J., Rozario, P.A., Tang, F., 2003. Effects of volunteering on the well-being of older adults. J. Geront. B Psychol. Sci. Soc. Sci. 58 (3), S137-S145. http://dx.doi.org/10.1093/geronb/58.3.s137.

Musick, M.A., Herzog, A.R., House, J.S., 1999. Volunteering and mortality among older adults: findings from a national sample. J. Geront. B Psychol. Sci. Soc. Sci. 54 (3), S173-S180. http://dx.doi.org/10.1093/geronb/54b.3.s173.

Numan, M., 2006. Hypothalamic neural circuits regulating maternal responsiveness toward infants. Behav. Cogn. Neurosci. Rev. 5 (4), 163-190. http://dx.doi.org/ $10.1177 / 1534582306288790$.

Okun, M.A., Yeung, E.W., Brown, S., 2013. Volunteering by older adults and risk of mortality: a meta-analysis. Psychol. Aging 28 (2), 564-577. http://dx.doi.org/ 10.1037/a0031519.

Post, S.G., 2005. Altruism, happiness, and health: it's good to be good. Int. J. Behav. Med. 12, 66-77. http://dx.doi.org/10.1207/s15327558ijbm1202_4.

Poulin, M.J., Brown, S.L., Dillard, A.J., Smith, D.M., 2013. Giving to others and the association between stress and mortality. Am. J. Public Health 103 (9), 1649-1655. http://dx.doi.org/10.2105/ajph.2012.300876.

Preston, S.D., de Waal, F.B.M., 2002. Empathy: its ultimate and proximate bases.
Behav. Brain Sci. 25 (01), 1-72. http://dx.doi.org/10.1017/s0140525x02000018.

Raposa, E.B., Laws, H.B., Ansell, E.B., 2016. Prosocial behavior mitigates the negative effects of stress in everyday life. Clin. Psychol. Sci. 4 (4), 691-698. http:// dx.doi.org/10.1177/2167702615611073.

Rosseel, Y., 2012. Iavaan: an R package for structural equation modeling. J. Stat. Softw. 48 (2), 1-36. http://dx.doi.org/10.18637/jss.v048.i02.

Sear, R., Coall, D.A., 2011. How much does family matter? Cooperative Breeding and the Demographic Transition. Pop. Dev. Rev. 37, 81-112. http://dx.doi.org/ 10.1111/j.1728-4457.2011.00379.x.

Sear, R., Mace, R., 2008. Who keeps children alive? A review of the effects of kin on child survival. Evol. Hum. Behav. 29, 1-18. http://dx.doi.org/10.1016/ j.evolhumbehav.2007.10.001.

Stadelman-Steffen, I., Freitag, M., 2011. Making civil society work: models of democracy and their impact on civic engagement. Nonprofit Volunt. Sect. Q. 40, 526-551. http://dx.doi.org/10.1177/0899764010362114.

Tanskanen, A.O., Danielsbacka, M., 2012. Beneficial effects of grandparental involvement vary by lineage in the UK. Pers. Individ. Dif. 53 (8), 985-988. http://dx.doi.org/10.1016/j.paid.2012.07.019.

Tanskanen, A.O., Danielsbacka, M., 2016. Do volunteering and charity pay off? wellbeing benefits of participating in voluntary work and charity for older and younger adults in Finland. Res. Ageing Soc. Policy 4 (2), 2-28. http://dx.doi.org/ 10.17583/rasp.2016.1640.

Taylor, M.F., Marquis, R., Batten, R., Coall, D.A., 2016. Understanding the mental health travails of custodial grandparents. Occup. Ther. Ment. Health 32 (3), 259-280. http://dx.doi.org/10.1080/0164212X.2015.1136255.

Tun, P.A., Miller-Martinez, D., Lachman, M.E., Seeman, T., 2013. Social strain and executive function across the lifespan: the dark (and light) sides of social engagement. Aging Neuropsychol. Cog 20 (3), 320-338. http://dx.doi.org/ 10.1080/13825585.2012.707173.

Van der Maas, P.J., Van Delden, J.J.M., Pijnenborg, L., Looman, C.W.N., 1991. Euthanasia and other medical decisions concerning the end of life. Lancet 338, 669-674. http://dx.doi.org/10.1016/0140-6736(91)91241-L.

WHO, 2012. European Health Report. http://www.euro.who.int/_data/assets/pdf_ file/0003/185214/Demographic-change-life-expectancy-Fact-Sheet.pdf (Accessed 2 December 2014).

Wilson, K.G., Graham, I.D., Viola, R.A., Chater, S., de Faye, B.J., Weaver, L.A., Lachance, J.A., 2004. Structured interview assessment of symptoms and concerns in palliative care. Can. J. Psychiatry 49, 350-358. https://ww1.cpa-apc. org/Publications/Archives/CJP/2004/june/wilson.pdf (Accessed 3 October 2014). 